\title{
Affordances of mobile devices and note-taking apps to support cognitively demanding note-taking
}

\author{
Mari van Wyk ${ }^{1}$ (D) Linda van Ryneveld ${ }^{1}$
}

Received: 20 September 2017 / Accepted: 20 December 2017 / Published online: 4 January 2018

(C) The Author(s) 2018. This article is an open access publication

\begin{abstract}
Note-taking is one of the more common and ever-present learning activities that form an important part of all students' daily lives. The potential of using technology to enhance note-taking activities has recently come under the spotlight. However, while mobile technologies may be applauded for their mobility and the value they can add to students' learning experience, they could easily become a distracting factor, rather than the improvement they were intended to be. In this qualitative study, eight students volunteered to experiment with various mobile devices for a period of 6 weeks, and to share their experiences in a series of five group interviews. Information found in the literature about note-taking, combined with the students' feedback on their experiences, provided insight into how students record and process information. The affordances of mobile devices for cognitively demanding note-taking that are regarded as useful in a teaching and learning environment were also discussed in the group interviews. All the students agreed that they would not commit themselves to using only one application or device. They emphasised the fact that they used more than one device, and in some cases multiple applications on those devices, depending on their educational setting. This article gives students, lecturers and software developers insight into the affordances of mobile devices and note-taking applications (apps), in order to support cognitively demanding note-taking.
\end{abstract}

Keywords Note-taking $\cdot$ Note-taking applications $\cdot$ Mobile devices $\cdot$ Tablets $\cdot$ Mobile phones · Laptops

Mari van Wyk

vanwykm@tut.ac.za

Linda van Ryneveld

linda.vanryneveld@up.ac.za

1 Department of Science, Mathematics and Technology Education, Faculty of Education, University of Pretoria, Natural Sciences Building 4-21, Groenkloof Campus, Pretoria, South Africa 


\section{Introduction}

Despite the fact that many university lecturers have embraced innovative teaching methods such as peer teaching and flipped classrooms, some still spend most of their time in class, lecturing in the traditional way as they have always done (Bui et al. 2013). Therefore, it is perhaps not surprising that many students still franticly take notes in class in the twenty-first century. Note-taking is the one activity that lecturers do not need to actively encourage, as students seem to take notes automatically (Morrison et al. 2002; Bui et al. 2013) without being prompted to do so. Regardless of previous research that claims that computers can be used for note-taking (Bui et al. 2013), many students still use the pen-and-paper method. Current researchers support this finding by confirming that if students take notes with a mobile device such as a laptop, they mechanically transcribe what the lecturer is saying, which results in shallow cognitive processes (Mueller and Oppenheimer 2014). The dilemma faced by lecturers is that students are constantly attached to their mobile devices (Maclachlan 2016) and that it therefore seems worthwhile to explore ways in which those mobile devices can be used for educational purposes.

As the process of note-taking is associated with action words and phrases such as capture, recall (Piolat et al. 2004), learn, remember (Anderson and Armbruster 1986), pay attention, organise, record, and making understandable and legible notes (Bui and Myerson 2014), this article focuses on the affordances of mobile devices that make it possible for students to take cognitively demanding notes. For this study, "affordances of mobile devices" refers to those qualities and properties that mobile devices offer to enable cognitively demanding note-taking, while "cognitively demanding note-taking" refers to the cognitive processes that take place during note-taking, and not to the notetaking itself that is cognitively demanding. Student participants experimented with mobile devices in various educational settings and their experiences were recorded and analysed. The affordances of mobile devices that support note-taking were subsequently identified from the feedback.

\section{The value of note-taking as a learning activity}

Much has been written about the educational importance to students of note-taking. For example, the researchers Anderson and Armbruster (1986), Ward and Tatsukawa (2003) and Kobayashi (2006) found that students learn and remember information when they take notes, and are able to retrieve that information at a later stage. This phenomenon was explained by Bui et al. (2013), who stated that the more notes students record, the stronger the influence it has on their learning, as more information is processed. As far back as 1925, Crawford (1925) found what Boyle and Forchelli (2014) confirmed in a more recent study, namely that if high-quality notes are recorded, learning and comprehension of material improve.

Students often complain about the balancing act they need to perform in class by simultaneously trying to read from slides, listen to the lecturer, critically engage with new constructs, and write legible notes. This is confirmed by Piolat et al. (2004) and Bui et al. (2013), who state that the process of note-taking is cognitively demanding. University students, and first-year students in particular, have been battling with the 
question of how to capture and recall the flow of information in traditional lecture periods for many years (Piolat et al. 2004). This may be because students who take notes need to pay attention, organise the information, and then record it in an understandable manner before it is forgotten (Bui and Myerson 2014).

If the process of taking notes is so demanding, the obvious question is why lecturers do not simply provide students with sets of comprehensive and well-written notes. Russell et al. (1983) found that if notes are provided it is better to give students partial outlines only, as opposed to full sets of notes, as that enables them to add their own experiences and observations, and thereby expand on the existing information. Also, Anderson and Armbruster (1986) claim that the act of note-taking assists the student with learning and remembering information, and with storing it for later use.

The way in which students take notes differs from student to student, and from educational setting to educational setting (Ward and Tatsukawa 2003; Badger et al. 2001; Bui et al. 2013; Boyle and Forchelli 2014). Two ideas for further research that emerged from the work of Boyle and Forchelli (2014) were that researchers needed to investigate the use of notes in different content areas in the real world of the student, and that the impact of technology on note-taking skills should be examined. To respond to this call, this article looks at the affordances of mobile devices that support cognitively demanding note-taking.

\section{Note-taking with an electronic device}

In the past decade many researchers advocated the use of computers (Bui et al. 2013) and electronic note-taking systems (Ward and Tatsukawa 2003; Kim et al. 2009) for recording and summarising important concepts in class. Bui et al. (2013) did a study where they compared pen-and-paper note-taking with taking notes on the computer. The authors found that although there was no difference in recalling information, the computer was better for transcribing notes than for organising them. In that particular study, transcribing referred to typing or writing as many facts as possible, while organising involved summarising facts before and while typing or writing them.

Furthermore, when students were tested immediately after they had taken the notes, the students who transcribed the notes achieved better scores than those who first organised them. However, when there was a time delay, students who first organised their notes were more successful. When the researchers allowed students who had only transcribed the notes to study them as well, the advantage that the students who had organised the notes had over time fell away. From the above, the assumption is made that computers can indeed be used for note-taking with some level of success. However, care needs to be taken, because if one wants to engage the student's mind, notetaking needs to be cognitively challenging, with technology playing a supporting role (Ward and Tatsukawa 2003), rather than it being a distracter in class (Mueller and Oppenheimer 2016).

In a contrasting study, Mueller and Oppenheimer (2014) wrote that when students record notes with a laptop instead of in the traditional way with a pen and paper, their immediate cognitive processing are deemed to be shallow. The authors argued that this is because students typically attempt to transcribe everything the lecturer says verbatim. Furthermore, when students in this study had to take a test, the ones using the laptop 
performed worse in conceptualising questions than the students who took notes with pen and paper. In another study (Vincent 2016), students also agreed that their handwritten notes led to a better retention of knowledge than when they typed their notes on an electronic device. Nevertheless, in spite of the disadvantages of taking notes on such devices, Vincent (2016) still argues that reading and writing online are more practical in a university environment than the known traditional methods.

\section{The availability of mobile devices}

Nowadays, most people seem to have access to mobile devices. Global statistics indicate that smartphone ownership worldwide has increased by $25 \%$ since 2013 (Poushter 2016), while global mobile device subscription rates reached 63\% in 2015 (Abbassi 2016). This trend of owning a smartphone also seems to be true for university students. Research done at universities in the United States (Poll 2015), United Kingdom (Deloitte 2016), Australia (Farley et al. 2015), Saudi Arabia (Alfawareh and Jusoh 2014) and South Africa (Potgieter 2015) shows that between 86 and 94\% of all higher education students own a smartphone. Although Statistics South Africa shows that only $35 \%$ of South Africans own a smartphone (Poushter 2016), in comparison with the $95 \%$ that own a mobile phone (Statistics South Africa 2014 2013), Potgieter's (2015) research shows that there seems to be more smartphone users at South African universities (86-94\%).

Students in the twenty-first century are accustomed to using technology (Maclachlan 2016). They do not own only smartphones, but also other mobile devices such as tablets and laptops, and they often choose to use these devices during class time. Together with smartphones, these mobile devices offer lecturers and their students a wide variety of tools and functionalities with educational potential. For example, students can use cameras, microphones and e-book readers for various learning purposes, and can receive instant feedback on their learning through a variety of messaging applications (Ifenthaler and Schweinbenz 2013). In another example, Alvares et al. (2011) mention that tablets can be used to improve the sharing of ideas when students work in groups. It thus seems as if many of the brick-and-mortar classroom boundaries disappear when mobile devices are used in an educational setting, and, as an added bonus, this learning environment without boundaries moves with the students wherever they go (Martin and Ertzberger 2013; Farley et al. 2015).

While students attend classes they have to take proper notes that capture the true essence of the class. However, they are not bound to one venue, and constantly have to move from one educational environment to another carrying all their handwritten notes with them. In some practical classes it is also not possible to sit down and write legible notes while a lecturer is busy with a demonstration. Therefore, since mobile devices such as laptops, tablets and smartphones are popular and available, their ability to support students with note-taking should be explored. It might be too optimistic to assume that all possible functionalities that students need to take efficient notes in all learning environments and for all learning purposes could be available in a single application on a single device 1 day. However, it may be worthwhile to explore the current affordances of mobile devices and applications that have the potential to support cognitively demanding note-taking in a variety of learning environments. 


\section{Methodology}

\subsection{Case study design}

This qualitative case study is explorative by nature and was conducted in the natural learning environment (Creswell 2007:37) of students at a university in South Africa that offers an undergraduate bachelor's degree in veterinary science (BVSc). According to Yin (2009), when "what?" questions are asked, the research can lead to the use of explorative case studies. Explorative case studies work best when little is known about the topic, as was the case in this study where the affordances of mobile devices and applications in various educational environments still had to be discovered.

\subsection{Participants}

The study was conducted in two separate phases. In Phase 1 of the project, the total group of second- to fourth-year pre-clinical veterinary science students $(n=365)$ was approached to participate in the study. A total of 179 students from this group completed an electronic questionnaire about their current access to, and use of, mobile devices for learning purposes. This questionnaire was administered by the researchers and after the purpose had been explained and consent asked, clickers were used to collect the students' responses. These responses were counted and summarised using Microsoft Excel.

In the last question of the questionnaire, student volunteers were invited to participate in this study. A group of eight second- to fourth-year students volunteered to explore the note-taking possibilities of mobile devices in various educational settings. The students' distribution in terms of their academic year, gender, mobile devices owned, internet access and residence is shown in Table 1.

\subsection{Research design}

Group interviews were used to bring about interaction between group members and to generate responses in an environment where students are free to respond to questions as they see fit (Harrell and Bradley 2009). Data was collected in a series of five group interviews. During each contact session the students were informed of the area of interest they had to explore during the following week and they were asked to identify the device and applications they intended to use for note-taking purposes that week. It

Table 1 Student distribution

\begin{tabular}{|c|c|c|c|c|}
\hline $\begin{array}{l}\text { Programme and } \\
\text { year }\end{array}$ & Gender & $\begin{array}{l}\text { Mobile } \\
\text { devices }\end{array}$ & Internet & Residence \\
\hline $\begin{array}{l}\text { One second-year } \\
\text { student }\end{array}$ & $\begin{array}{l}\text { Six females } \\
\text { Two males }\end{array}$ & $\begin{array}{l}\text { Smart phones } \\
\text { Tablets }\end{array}$ & $\begin{array}{l}\text { All had internet } \\
\text { access. }\end{array}$ & $\begin{array}{l}\text { Three lived off } \\
\text { campus. }\end{array}$ \\
\hline $\begin{array}{l}\text { Five third-year } \\
\text { students }\end{array}$ & & $\begin{array}{l}\text { Laptops } \\
\text { Kindle }\end{array}$ & & $\begin{array}{l}\text { Three stayed in the } \\
\text { residence on campus. }\end{array}$ \\
\hline $\begin{array}{l}\text { Two fourth-year } \\
\text { students }\end{array}$ & & & & $\begin{array}{l}\text { Two did not disclose } \\
\text { where they stayed. }\end{array}$ \\
\hline
\end{tabular}


is important to note that no mobile devices were provided for the purpose of the study. The participating students all owned their own mobile devices and they only had to make a selection if they owned or had access to more than one device, for example, a laptop and a smart phone. No level of prior knowledge about the use of mobile devices was assumed, and the students did not receive training of any kind, as the researchers were interested in the students' authentic experience, without external interference of any kind. Students were simply asked to experiment and explore ways to use their various mobile devices and associated applications to record notes, and they were free to use the device(s) of their choice, such as a laptop, a tablet or a smartphone.

The participants had to inform the researchers in which module and learning context they would be testing their technology-supported note-taking efforts. In each of the group interviews, the participants were asked to report on their experience with the specific device and applications that they used for taking notes, and on whether or not they felt it worked for them. The weekly activities varied from identifying different apps to use for note-taking in a lecture to creating open educational resources that could be shared amongst students, as indicated below:

- Select a mobile device, and use it for note-taking purposes

- Explore existing open educational resources from your mobile device, and relate what you find to one of your subject modules.

- Use the multimedia features of your mobile device to record photos, audio and videos as part of note-taking.

- Create an open educational resource by combining your notes (Week 1), existing open educational resources (Week 2) and multimedia (Week 3).

- Upload your open educational resource to an electronic platform such as a learning management system or YouTube and share the link with your fellow students.

\subsection{Data analysis}

The research team's representation was constructed based on the rich descriptions of the participants' feedback and views when they discussed how they had used their mobile devices and applications as note-taking tools in their day-to-day academic lives (Creswell 2007; Miles and Huberman 1994:11). The feedback received in the group interviews was recorded and transcribed and the text was analysed, as described by Henning et al. (2004), to determine trends and recurring patterns. The participants' feedback was coded according to a group and participant number. For example, the code G1P5 represents feedback given by participant number five in the first group interview.

\section{Results and discussion}

To confirm the usage of mobile devices at this university, the participants were asked in the first phase of the study to indicate what mobile devices they were using at that time. In the electronic questionnaire, $96.6 \%$ of the students indicated that they were using mobile devices. The various mobile devices that students used are indicated in Table 2. 
Table 2 Mobile devices used

\begin{tabular}{ll}
\hline Device & Number of students \\
\hline Laptop & 156 \\
Tablet & 77 \\
Smartphone & 146 \\
None & 6 \\
\hline
\end{tabular}

Students also specified that they use their mobile devices for both social and academic purposes. This is shown in Table 3.

From these results it is clear that the students were already using mobile devices intuitively for either taking notes or recording lectures during class time. Thirty-one percent of the students participating in this study indicated that they used their mobile devices for taking notes during classes, $61 \%$ of the students used their mobile devices for taking photographs during class, while $22 \%$ of the students had recorded a lecture in the past.

In the second phase of this study, the student participants experimented with different types of mobile devices and applications in various educational settings. Between them, the participants owned and used devices such as tablets, smartphones, video cameras, action cameras, Kindles and laptops. These devices were used to take notes in class through typing text, inserting photographs and self-drawn sketches, recording audio and video clips, and then integrating the different components into learning notes that could be used for studying. To do so, students not only experimented with the functionalities of the various mobile devices, but also with a number of applications (apps) that lend themselves to note-taking.

\subsection{Open and edit existing notes}

Students who want to take notes need to be able to create a blank document for entering their personalised notes. However, in some cases lecturers provide full or partial notes

Table 3 Social and academic use of mobile devices

\begin{tabular}{llll}
\hline $\begin{array}{l}\text { Mobile device used for social } \\
\text { purposes }\end{array}$ & $\begin{array}{c}\text { Number } \\
\text { students }\end{array}$ & $\begin{array}{l}\text { Mobile devices used for academic } \\
\text { purposes }\end{array}$ & $\begin{array}{c}\text { Number of } \\
\text { students }\end{array}$ \\
\hline Social media & 158 & Not using it for academic purposes & 16 \\
Email & 148 & Searching information & 142 \\
SMS & 146 & Accessing Blackboard & 116 \\
Instant messaging & 132 & Taking notes & 55 \\
Videos and music & 132 & Taking photographs & 109 \\
News and weather & 101 & Recording lecturers & 39 \\
Browsing & 129 & Doing assignments and tests & 61 \\
Games & 90 & Discussion groups & 70 \\
Calendar & 110 & Other & 16 \\
Other & 27 & & \\
\hline
\end{tabular}


before the class. Russell et al. (1983) emphasise the value of having partial notes available when recording important information in class, and add that partial notes allow students to add their own personal experience and understanding to the notes. By doing so, they are able to supplement the existing information. In this study, the participants indicated that they needed to be able to create a blank document if the lecturer's notes and PowerPoint presentations were not available electronically before class. If those notes were available, they needed to be able to open them on the devices of their choice. This need to have notes available before class and to have them available on a mobile device was confirmed during one of the group interviews where one student mentioned that:

"... and it would really be more efficient if we could have them with us in class available ... I really like using my tablet so that I don't have to print all the colour pictures because it gets really costly. So I would like to have it on my tablet. Download it the night before and be able to type extra notes on there." [G1P1]

\subsection{Input mode}

To take notes on these mobile devices, the participants used either a stylus or a keyboard to capture information. The ones who explored note-taking with a stylus had mixed success. For example, the mobile devices with a dedicated stylus seemed to work better for writing notes and drawing sketches than those that required students to install a specific application to enable them to write with. This mixed success is demonstrated in the comments of two student participants:

"Whereas now with the Samsung and its stylus it is one of the first ones they have actually brought out where the palm recognition is correct and it does not make lines all over the page and that really has made it a lot easier." [G1P5]

"I did download a stylus beta app to try and use the stylus but your finger recognition is a lot better than the stylus. Then when it tries to convert the handwriting to text its one big mission so I just decided to rather type." [G2P1]

For those participants who were able to type fast, the keyboard seemed to have worked well. They reported that the keyboard allowed them to capture a large number of notes.

"I've got a little memo pad app on my cellphone and I type crazy fast on my cellphone so I sit and type what the lecturer says." [G1P6]

However, according to the literature, the use of the keyboard could potentially hinder cognitively demanding processes, and only allow students to transcribe verbatim what the lecturer was saying (Mueller and Oppenheimer 2014). Therefore, although the keyboard is the most common way of entering information on a mobile device, it might add value for cognitively demanding note-taking purposes if the mobile device could have a dedicated stylus. All the students agreed that a stylus would enable them to take notes in the way they wanted to. 
"I don't like trying to type what the lecturer is saying as he is saying it I will write something in bullet format and then link it to something else. Whereas now with the Samsung and its stylus ... I can actually take notes the way I want to." [G1P5]

A number of different word processing applications were tested for entering the information, which allowed the participants to type text, format it and insert objects. The participants found that not all word processing applications that were available on their smartphones and tablets had the same functionalities as those that they were used to on their computers. This could be the result of students having inexpensive, entry-level smartphones. Even when working with dedicated note-taking applications, the participants found that some applications allowed them to open, edit and save documents, and that others limited them to only opening and viewing existing documents. Although Bui et al. (2013) found that the more information students recorded, the higher the influence it had on learning, researchers seem to agree that it is not necessarily the ability to speedily record information that adds value to the note-taking process, but rather the way in which students need to pay attention, organise the information and record it in an understandable way (Bui and Myerson 2014) that made note-taking cognitively demanding (Piolat et al. 2004). It seemed that some students put so much effort into working with the application that they did not spend time on the note-taking per se.

As mentioned by a participant, it would be of value if the note-taking application allowed students to draw shapes and diagrams rather than only allowing text input. These drawings could either be added to existing notes (for example, on PowerPoint presentations that are made available in a PDF format) or to a blank document. To make notes clear and legible, it might be worthwhile to also explore handwriting recognition possibilities. In addition, regular formatting functions (bold, italics, font colour, etc.) should be in place so that students can emphasise certain information. Given these affordances, the quality of the notes could be improved significantly while learning comprehension would increase, as research has proved the correlation between the quality of notes and the degree of learning comprehension (Boyle and Forchelli 2014).

\subsection{Using the camera}

The participants in the study used more than the typing functionality of their mobile devices when they took their notes. Some of them also used the camera functionalities of their mobile phones or tablets to take photos and/or to record audio and video clips. These photos were then combined with their other learning materials and they could write next to the photo or on it. For example, one student mentioned that she had added a screen clipping to her note-taking application and then she could type next to it, or on it, while the lecturer was lecturing.

"Then you highlight the piece you want [and] put it in there. You can [then] type next to it, [or] you can type on top of it." [G2P6]

Initially, students were excited to video record their lectures as an alternative to taking notes in the more traditional way. However, most of them agreed that when they recorded a lecture in its entirety, they very seldom went back to watch it again. 
"I always make hand notes irrespective of taking a video. I still would more default to my own hand notes trying to understand. It is a lot quicker than sitting through another two hours through class trying to find out what he said." [G3P1]

"If I sleep through most of the lectures in class then I will definitely sleep again in my room." [G3P4]

The only exception was if they had missed a class and could catch up by watching a video that had been recorded by a fellow student who did attend the session. However, the participants found the videos they recorded during the practical sessions very useful, for example, when a clinician demonstrated a particular procedure. In these practical sessions, the participants used their smartphones to record the lesson. Although a smart phone's video quality was good enough, participants stated that the advantage of smartphone videos and photos was that they were immediately available on the mobile device and could easily be manipulated afterwards. However, highquality smartphone videos and photos were only possible if the recording student was in a position to get a clear view of the demonstration. The participants also appreciated the fact that such videos were then available on demand, regardless of where the viewers were.

\subsection{Accessibility of notes}

Because the participants moved between different educational settings in the course of a typical week, they indicated a need to use various mobile devices, depending on the context. For example, participants found it difficult to sit down and type while they were observing a practical demonstration with live cattle. As such, the participants found that they ended up with a lot of worthwhile notes on a particular topic, but that those notes were dispersed over multiple devices. Therefore, in an attempt to combine all the notes that were recorded using the various devices into a comprehensive document that could be used for studying purposes, participants reported that they needed to share their notes and artefacts between devices.

"So if you've got multiple resources on one single device then you have the chance to look at it immediately." [G1P6]

However, some participants seemed to find it difficult to share information between devices because they could not get the devices to communicate with one another. Some participants reported that their devices had USB adaptors with which notes could easily be shared between devices. Others were creative and came up with innovative solutions in this regard. They captured notes on one device, such as their smartphone, and then emailed the document or artefact to themselves so that they could download and access it on their laptop or tablet via their mailing system. It was not always possible to use the same device when students moved between various educational settings; therefore, it would help if the note-taking application made it easy for students to share information between devices so that they could have all the information on one device. 
"You can't really only have one device and expect to use it all the time. Unfortunately it is not practical." [G1P6]

\subsection{Organising and sharing notes}

To keep the notes they had taken for revision purposes and to study from them at a later stage, the participants needed to organise the work in folders and to save the notes in a way that supported their personal learning preferences. However, some participants complained that there was insufficient storage space on their devices. Therefore, the note-taking application should also allow students to change the storage location to accommodate cloud or external memory card storage.

Although the participants used mobile devices and stored information on their personal devices, that stored information needs to integrate seamlessly with the learning management system used by the universities, as this is the platform on which notes for student downloading are stored.

"So if we could have the slideshows ... and then to make notes on top of that would be very valuable. So for them to upload it before class is what we are basically asking." [G1P6]

\subsection{Educational gains through using mobile devices for note-taking}

While the students struggled in some instances to use mobile devices and applications for note-taking purposes, they certainly also gained from using those devices and applications. These educational gains are reflected in the discussion above and in the comments students made at the end of the research study. For example, when taking notes on mobile devices, students can combine typed notes with handwritten notes as well as incorporating media such as pictures and videos. When doing so, all their notes on a particular topic are saved in one location.

Furthermore, students mentioned that their notes were available anywhere and at any time because they had those notes on their mobile devices. If they also had electronic versions of their textbooks, it would be possible to have their books and notes available on one mobile device that moves with them wherever they go, whether it is a classroom, hospital or veterinary practice. As one student mentioned:

"...to have my slideshows with me and to have mobile books and stuff all in the same convenient small little thing. Because lugging a book like that around is a nightmare, and I am somebody that if I don't understand something I want to look it up now, because you tend to forget, or you think it's not that important you end up not looking at it." [G1P6]

One participant incorporated the video and pictures taken during practical demonstrations into the PowerPoint slideshow the lecturer provided. This integration process formed a significant part of the participant's studying. She stated: 
"Now I've learned to incorporate videos and pictures into the PowerPoint slide that the lecturer has given to us. ... It has helped me with my marks because now I put in more effort in my studying and it has paid off in most of my marks. ... Also knowing that this PowerPoint slide helped me. I can give it to someone else next year whom it's going to help and that person can modified it ..." [G5P2]

\section{Note-taking application affordances}

In view of the above, it is evident that not all of the functions the student participants wanted to use worked seamlessly on the same device or were available in one application. For example, certain aspects need to be available on such an application in order to take notes. The note-taking functionalities with which the student participants experimented and that need to be present in a note-taking application are as follows:

- Open and edit an existing document.

- Add notes via a physical or virtual keyboard.

- Add input via a handwriting functionality, possibly with handwriting recognition by means of, for example, a stylus.

- Write or draw directly on objects such as slides or PDFs with text, pictures and diagrams.

- Format text and paragraphs, for example, bold, italics, bullets, numerical lists.

- Insert and save multimedia such as photos, animations, audio clips and videos in the notes.

- Create folders for organisational purposes.

- Save notes; on the device, and/or on the cloud, and/or an external memory card.

- Access and share notes across multiple devices such as laptops, tablets and smartphones.

- Email notes.

The researchers realise that the affordances contained in this list might not only involve aspects that need to be addressed through software development, but that the hardware of the device also has to be suitable. For example, to be able to connect a USB device, there has to be a USB port or converter. Still, this list could be valuable to students when they need to evaluate and decide on which note-taking applications to use, as they often spend a lot of time downloading and installing an application and creating a user account, only to discover belatedly that the application does not meet their specific needs. In addition, this list could also be useful to software developers when they develop note-taking application software, whether for educational or business purposes. Furthermore, when lecturers want to recommend note-taking applications to students, this list could give them an idea of the functionalities such an application should incorporate.

The researchers acknowledge the importance of cognitive processes while taking notes, as indicated in the literature discussed earlier in the article. However, in this study, the identified affordances of mobile devices to support cognitively demanding 
note-taking were not tested. Therefore, it is suggested that further research needs to be done to determine whether these suggestions, when implemented, will support students to take notes on their mobile devices that involve cognitively demanding processes. The researchers also recognise the fact that this list of suggestions is not exhaustive and that there might be other factors that could also contribute to the development of notetaking devices and apps to take notes that are cognitively demanding. However, the suggestions made in this article resulted from the experience of students using mobile devices in their authentic educational environments. These students indicated their real struggle when trying to take notes, and therefore the researchers believe that more research and testing on both the hardware and software issues should be done with regard to taking notes with mobile devices. This study definitely indicates that students do not prefer one specific device above others, and the researchers therefore suggest that the note-taking software needs to be accessible from all the students' mobile devices, and that students be given the freedom to select the devices they prefer.

\section{Conclusion}

As mentioned previously, note-taking practices are still a standard learning activity of students in higher education. The cognitive processes that form part of note-taking are sometimes regarded as being more valuable than the rote actions of simply capturing information. Additionally, contrasting research results about the use of technology in the note-taking process were published over the years (Bui et al. 2013; Mueller and Oppenheimer 2014). Since students are seldom without their mobile devices, many lecturers are investigating ways in which these devices could be used for educational purposes such as note-taking. Despite students' apparent ease of access to and successful use of mobile devices in other contexts, the use of these devices for note-taking has been met with varied success.

Similarly to the way in which researchers value the worth of partial notes in cognitively demanding note-taking, students expressed the need to have an electronic copy of the lecturer's presentation available on their mobile devices before class so that they can open the notes beforehand and add their personal insights. In addition, students need to be able to write and type on their notes in order to be cognitively involved in the note-taking process. While all devices and applications allow keyboard input, not all of them make provision for students to write on their electronic notes.

Since the students who participated in this research moved between various educational settings, and because using the same type of device is not always practical in all kinds of environments, they used various devices. As a result, their note-taking activities varied from writing and typing in class to taking photos and videos in a practical demonstration. Therefore, to make sense of all the notes they took during the day or in one particular subject, they had to be able to merge the information they recorded. That could either be done by sending or saving all information on one device, or by combining it in one application so that the information could be accessed from all the devices used.

Although it is premature to assume that one application loaded on a single type of mobile device could give the students everything they need to take notes, the technology is developing rapidly and therefore it is anticipated that students will soon be able 
to use mobile devices and note-taking applications seamlessly and intuitively to enhance their note-taking practices.

This study, taking the student experience into consideration, suggests how the affordances of mobile devices could be mobilised for the process of taking cognitively demanding notes. These suggestions could possibly be of value to students, lecturers and software developers. However, the researchers are not convinced that it is possible to have all these affordances on one application or on one device at this stage, or that it is actually necessary to have all the functionalities of mobile devices that can be used for note-taking purposes available on one application. We did, however, find that when students experimented with these devices, some devices worked better in a particular educational setting than others. Therefore, additional research should be done to determine how these identified affordances of mobile devices could be further exploited to provide students with the means to use their mobile devices for cognitively demanding note-taking purposes.

Funding This work was supported by a NRF GRANT: THUTHUKA Funding Instrument (PhD Track).

\section{Compliance with ethical standards}

Conflict of interest The authors declare that they have no conflict of interest.

Informed consent After the participants had given written consent, data was collected electronically and is currently stored on a password-protected device. The raw data can be accessed with permission from the Ethics Committee.

Ethical approval Ethics approval was obtained from the Ethics Committee of the Faculty of Education, University of Pretoria, South Africa, and this study was thus guided by the University rules and regulations with regards to ethics.

Open Access This article is distributed under the terms of the Creative Commons Attribution 4.0 International License (http://creativecommons.org/licenses/by/4.0/), which permits unrestricted use, distribution, and reproduction in any medium, provided you give appropriate credit to the original author(s) and the source, provide a link to the Creative Commons license, and indicate if changes were made.

\section{References}

Abbassi, J. J. (2016). The mobile economy. https://www.itu.int/en/ITU-D/RegionalPresence/ArabStates/Documents/events/2016/RDF/Pres/S5-GSMA-The\%20Mobile\%20Economy.pdf. Accessed 8 Dec 2016.

Alfawareh, H. M., \& Jusoh, S. (2014). Smartphones usage among university students: Najran University case. International Journal of Academic Research Part B, 6(2), 321-326. https://doi.org/10.7813/20754124.2014/6-2/B.48.

Alvares, C., Brown, C., \& Nussbaum, M. (2011). Comparative study of netbooks and tablet PCs for fostering face-to-face collaborative learning. Computers in Human Behaviour, 27(2011), 834-844. https://doi. org/10.1016/j.chb.2010.11.008.

Anderson, T. H., \& Armbruster, B. B. (1986). The value of taking notes during lectures. Technical Report No. $374,1-48$.

Badger, R., White, G., Sutherland, P., \& Haggis, T. (2001). Note perfect: An investigation of how students view taking notes in lectures. System, 29, 405-417. https://doi.org/10.1016/S0346-251X(01)00028-8.

Boyle, J. R., \& Forchelli, G. A. (2014). Differences in the note-taking skills of students with high achievement, average achievement, and learning disabilities. Learning and Individual Differences, 35(2014), 9-14. https://doi.org/10.1016/j.lindif.2014.06.002. 
Bui, D. C., \& Myerson, J. (2014). The role of working memory abilities in lecture note-taking. Learning and Individual Differences, 33(2014), 12-22. https://doi.org/10.1016/j.lindif.2014.05.002.

Bui, D. C., Myerson, J., \& Hale, S. (2013). Note-taking with computers: Exploring alternative strategies for improved recall. Journal of Educational Psychology, 105(2), 299-309. https://doi.org/10.1037/a0030367.

Crawford, C. C. (1925). The correlation between college lecture notes and quiz papers. Journal of Educational Research, 12(4), 282-291. https://doi.org/10.1080/00220671.1925.10879600.

Creswell, J. W. (2007). Qualitative inquiry and research design: Choosing among five approaches (2nd ed.). Thousand Oaks: Sage.

Deloitte, L. L. P. (2016). There's no place like phone: Global Mobile Consumer Survey 2016. https://www. deloitte.co.uk/mobileuk/assets/pdf/Deloitte-Mobile-Consumer-2016-There-is-no-place-like-phone.pdf. Accessed 24 Jan 2017.

Farley, H., Murphy, A., Johnson, C., Carter, B., Lane, M., Midgley, W., Hafeez-Baig, A., Dekeyser, S., \& Koronios, A. (2015). How do students use their mobile devices to support learning? A case study from an Australian regional university. Journal of Interactive Media in Education, 1(14), 1-13. https://doi.org/10.5334/jime.ar.

Harrell, M. C., \& Bradley, M. A. (2009). Data collection methods: Semi-structured interviews and focus groups. Santa Monica: Rand National Defence Research Institute.

Henning, E., van Rensburg, W., \& Smit, B. (2004). Finding your way in qualitative research. Pretoria: Van Schaik.

Ifenthaler, D., \& Schweinbenz, V. (2013). The acceptance of tablet PCs in classroom instruction: The teachers' perspectives. Computers in Human Behaviour, 29(2013), 525-534. https://doi.org/10.1016/j. chb.2012.11.004.

Kim, K., Turner, S. A., \& Pérez-Qui-ones, M. A. (2009). Requirements for electronic note taking systems: A field study of note taking in university classrooms. Education and Information Technologies, 14(3), 255283. https://doi.org/10.1007/s10639-009-9086-z.

Kobayashi, K. (2006). Combined effects of note-taking/-reviewing on learning and the enhancement through interventions: A meta-analytic review. Educational Psychology, 26(3), 459-477. https://doi.org/10.1080 /01443410500342070.

Maclachlan, M. (2016). Why pen and paper beats a laptop every time for taking notes. https://www. communicaid.com/communication-skills/blog/writing-skillsbusiness-writing-skills/taking-notes-betterusing-laptop-tablet/. Accessed 28 Apr 2017.

Martin, F., \& Ertzberger, J. (2013). Here and now mobile learning: An experimental study on the use of mobile technology. Computers \& Education, 68(2013), 76-85. https://doi.org/10.1016/j.compedu.2013.04.021.

Miles, M. B., \& Huberman, A. M. (1994). Qualitative data analysis (2nd ed.). Thousand Oaks: SAGE Publications.

Morrison, E. H., McLaughlin, C., \& Rucker, L. (2002). Medical students' note-taking in a medical biochemistry course: An initial exploration. Medical Education, 36, 384-386. https://doi.org/10.1046/j.13652923.2002.01167.x.

Mueller, P. A., \& Oppenheimer, D. M. (2014). The pen is mightier than the keyboard: Advantages of longhand over laptop note taking. Psychological Science, 25(6), 1159-1168. https://doi.org/10.1177 /0956797614524581.

Mueller, P. A., \& Oppenheimer, D. M. (2016). Technology and note-taking in the classroom, boardroom, hospital room and courtroom. Trends in Neuroscience and Education, 5, 139-145. https://doi.org/10.1016 j.tine.2016.06.002.

Piolat, A., Olive, T., \& Kellogg, R. T. (2004). Cognitive effort during note taking. Applied Cognitive Psychology, 19, 291-312. https://doi.org/10.1002/acp.1086.

Poll, H. (2015). Pearson student mobile device survey. National Report: College Students, June 2015. http:/www.pearsoned.com/wp-content/uploads/2015-Pearson-Student-Mobile-Device-Survey-College. pdf. Accessed 24 Jan 2017.

Potgieter, A. (2015). The mobile application preferences of undergraduate university students: A longitudinal study. South African Journal of Information Management, 17(1), 1-6. https://doi.org/10.4102/sajim.v17i1.650.

Poushter, J. (2016). Smartphone ownership and internet usage continue to climb in emerging economics. http://www.pewglobal.org/2016/02/22/smartphone-ownership-and-internet-usage-continues-to-climb-inemerging-economies/. Accessed 8 Dec 2016.

Russell, I. J., Caris, T. N., Harris, G. D., \& Hendricson, W. D. (1983). Effects of three types of lecture notes on medical student achievement. Journal of Medical Education, 58, 627-636. https://doi.org/10.1097 /00001888-198308000-00004.

Vincent, J. (2016). Students' use of paper and pen versus digital media in university environments for writing and reading - A cross-cultural exploration. Journal of Print Media and Media Technology Research, 5(2), 97-106.

Ward, N., \& Tatsukawa, H. (2003). A tool for taking class notes. International Journal of Human-Computer Studies, 59, 959-981. https://doi.org/10.1016/j.ijhcs.2003.07.003.

Yin, R. K. (2009). Case study research design and methods (4th ed.). Thousand Oaks: SAGE Publications. 